\title{
Inulin and levan synthesis by probiotic Lactobacillus gasseri strains: characterization of three novel fructansucrase enzymes and their fructan products
}

\begin{abstract}
Correspondence
Lubbert Dijkhuizen

L.Dijkhuizen@rug.nl
\end{abstract}

Received 21 November 2009

Revised 6 January 2010

Accepted 12 January 2010

\author{
Munir A. Anwar, Slavko Kralj, † Anna Villar Piqué, Hans Leemhuis, \\ Marc J. E. C. van der Maarel and Lubbert Dijkhuizen
}

Microbial Physiology Research Group, Groningen Biomolecular Sciences and Biotechnology Institute (GBB), University of Groningen, Kerklaan 30, 9751 NN Haren, The Netherlands

\begin{abstract}
Fructansucrase enzymes polymerize the fructose moiety of sucrose into levan or inulin fructans, with $\beta(2-6)$ and $\beta(2-1)$ linkages, respectively. Here, we report an evaluation of fructan synthesis in three Lactobacillus gasseri strains, identification of the fructansucrase-encoding genes and characterization of the recombinant proteins and fructan (oligosaccharide) products. High-performance anion-exchange chromatography and nuclear magnetic resonance analysis of the fructo-oligosaccharides (FOS) and polymers produced by the $L$. gasseri strains and the recombinant enzymes revealed that, in situ, L. gasseri strains DSM 20604 and 20077 synthesize inulin (and oligosaccharides) and levan products, respectively. L. gasseri DSM 20604 is only the second Lactobacillus strain shown to produce inulin polymer and FOS in situ, and is unique in its distribution of FOS synthesized, ranging from DP2 to DP13. The probiotic bacterium L. gasseri DSM 20243 did not produce any fructan, although we identified a fructansucrase-encoding gene in its genome sequence. Further studies showed that this L. gasseri DSM 20243 gene was prematurely terminated by a stop codon. Exchanging the stop codon for a glutamine codon resulted in a recombinant enzyme producing inulin and FOS. The three recombinant fructansucrase enzymes characterized from three different $L$. gasseri strains have very similar primary protein structures, yet synthesize different fructan products. An interesting feature of the $L$. gasseri strains is that they were unable to ferment raffinose, whereas their respective recombinant enzymes converted raffinose into fructan and FOS.
\end{abstract}

\section{INTRODUCTION}

A diverse number of naturally occurring Lactobacillus species inhabit the gastrointestinal (GI) tract of humans and animals and are widely considered to exert a number of beneficial effects on human health. Lactobacillus gasseri, which is speculated to be an autochthonous human

†Present address: Genencor-A Danisco Division, Archimedesweg 30, 2333 CN, Leiden, The Netherlands.

Abbreviations: FOS, fructo-oligosaccharides; FTF, fructosyltransferase; Gl, gastrointestinal; HPAE, high-pressure anion-exchange [chromatography]; LB, Luria-Bertani; NMR, nuclear magnetic resonance.

The GenBank/EMBL/DDBJ accession numbers for the Lactobacillus gasseri ftf genes and their flanking regions are GU166814 (inuGB) and GU166815 (levG), and the nucleotide sequence data reported for inuGA are available in the Third Party Annotation section of the GenBank/ EMBL/DDBJ databases under the accession number TPA: BK006921.

Two supplementary figures and two supplementary tables are available with the online version of this paper. intestinal organism (Azcarate-Peril et al., 2008), constitutes a major part of the homofermentative Lactobacillus species occupying the human GI tract (Kullen et al., 2000). L. gasseri is associated with a variety of probiotic functions including reduction of activities of faecal mutagenic enzymes (Pedrosa et al., 1995), adherence to intestinal tissues (Conway et al., 1987; Kirjavainen et al., 1998), stimulation of macrophages (Kirjavainen et al., 1999; Tejada-Simon \& Pestka, 1999) and production of bacteriocins (Itoh et al., 1995). The probiotic role of several lactobacilli has been attributed to the synthesis of prebiotic fructose-based polysaccharides (fructans) from sucrose involving fructansucrase or fructosyltransferase (FTF) enzymes (Armuzzi et al., 2001; Korakli et al., 2002; Oda et al., 1983).

FTF enzymes possess either levan- or inulosucrase activity, polymerizing the fructose moiety of their substrate sucrose into fructans with either levan or inulin structures, with $\beta(2-6)$ and $\beta(2-1)$ linkages, respectively. Although all 
known lactic acid bacterial FTFs share a high amino acid sequence similarity $(>60 \%)$, it is not known which structural features determine the linkage type in their fructan products. Various groups have attempted to elucidate structure-function relationships of FTF enzymes, following site-directed mutagenesis and FTF protein 3D structure analysis. At present, high-resolution 3D structures are only available for the levansucrase proteins of Bacillus subtilis, also with sucrose and raffinose bound in the active site (Meng \& Futterer, 2003, 2008), and Gluconacetobacter diazotrophicus (Martinez-Fleites et al., 2005). It has been proven by site-directed mutagenesis that the amino acid residues located at the -1 (donor) and +2 (acceptor) sugar-binding subsites are important in determining the size of the products synthesized and polymer versus oligosaccharide product ratio (Homann et al., 2007; Ozimek et al., 2006a). A recent study on the B. subtilis levansucrase mutant G342A complexed with raffinose (FrcGlc-Gal) revealed that the galactosyl moiety of raffinose protruded out of the active site, while specificity-determining contacts were essentially restricted to the sucrosyl (Frc-Glc) moiety (Meng \& Futterer, 2008).

Currently, only six inulosucrase genes/enzymes have been characterized from Gram-positive bacteria, namely in Streptococcus mutans (Rosell \& Birkhed, 1974), Leuconostoc citreum CW28 (Olivares-Illana et al., 2002), Lactobacillus reuteri 121 (van Hijum et al., 2002), Bacillus sp. (Wada et al., 2003), L. reuteri TMW 1.106 (Schwab et al., 2007) and Lactobacillus johnsonii NCC 533 (Anwar et al., 2008), while numerous levansucrases are known (http://www.cazy.org/fam/GH68.html) from both Grampositive and Gram-negative bacteria. This limited knowledge of inulosucrase enzymes and lack of 3D structures hamper our efforts to understand the differences between inulo- and levansucrases.

Here, we describe the isolation and cloning of two $\mathrm{ft} f$ genes from two different L. gasseri strains, i.e. DSM 20604 and DSM 20077. These genes and the novel FTF enzymes that are encoded, an inulosucrase and levansucrase, are characterized in detail. We also report cloning (and restoration of enzyme activity by elimination of a preliminary stop codon) of an inulosucrase gene that was identified in the genome of the L. gasseri type strain DSM 20243.

\section{METHODS}

Amino acid sequence analysis. Multiple amino acid sequence alignments were made with CLUSTAL W 1.74 (Thompson et al., 1994). Specific features and the catalytic core of $L$. gasseri FTFs were deduced from these alignments along with the Pfam database (http://pfam. janelia.org) and the signal peptide cleavage sites of the FTFs were predicted using SignalP (http://www.cbs.dtu.dk/services/SignalP/).

Bacterial strains, plasmids and culture conditions. The L. gasseri DSM 20243, 20604 and 20077 strains were obtained from the DSMZ culture collection. L. reuteri 121 (LMG 18388) was obtained from the culture collection of TNO Nutrition and Food Research, The
Netherlands. For genomic DNA isolation, the cells were cultivated anaerobically at $37^{\circ} \mathrm{C}$ in MRS medium containing 20 g glucose $1^{-1}$. MRS with sucrose $\left(200 \mathrm{~g} \mathrm{l}^{-1}\right)$ instead of glucose, was used for polysaccharide production by these strains. Escherichia coli TOP10 (Invitrogen) and BL21 (DE3 star; Invitrogen) were used as hosts for cloning and expression purposes, respectively. Plasmid pET15b (Novagen) was used for expression of the $\mathrm{ftf}$ genes. E. coli transformations were performed by the heat shock method using chemically competent cells (Sambrook et al., 1989). E. coli strains were grown at $37{ }^{\circ} \mathrm{C}$ and shaking at 210 r.p.m. in Luria-Bertani (LB) medium supplemented with the appropriate antibiotic in order to maintain plasmid integrity $\left(100 \mu \mathrm{g}\right.$ ampicillin $\mathrm{ml}^{-1}$ or $50 \mu \mathrm{g}$ kanamycin $\mathrm{ml}^{-1}$ ). LB agar plates were made by adding $1.5 \%$ agar to the LB medium.

General molecular techniques. Genomic DNA of the three $L$. gasseri strains was extracted and purified using a genomic DNA purification kit (Sigma Aldrich). E. coli plasmid DNA was isolated using a plasmid miniprep kit (Sigma Aldrich). General procedures for cloning, DNA manipulations, transformations and agarose gel electrophoresis were performed as described by Sambrook et al. (1989). Restriction endonuclease digestions and ligations with T4 DNA ligase were performed as recommended by the supplier (Fermentas). DNA was amplified by PCR (PTC-200 Thermal Cycler, MJ Research), using high-fidelity DNA polymerase (Fermentas) for the standard and inverse PCRs. The TOPO XL PCR cloning kit (Invitrogen) was used for cloning and sequencing of the $\mathrm{ftf}$ genes, following the supplier's instructions. Oligonucleotides (Supplementary Tables S1 and S2, available with the online version of this paper) were purchased from Eurogentec. DNA fragments were isolated from agarose gels using a Qiagen extraction kit, following the supplier's instructions (Qiagen).

Isolation, cloning and sequencing of $\boldsymbol{L}$. gasseri ftf genes. The $\mathrm{ftf}$ gene fragment of L. gasseri DSM 20243 contained a naturally occurring early stop codon (TAA) at position 1954. Replacing the stop codon with a glutamine codon (CAA) resulted in a full-length $\mathrm{ftf}$ gene of $2367 \mathrm{bp}$ (designated inuGA) as described below. Using the specifically designed PCR primer set Lgas-F/Lgas-R, a truncated version of inuGA encoding aa 137-702 of the FTF protein (including 50 aa downstream of the stop codon), with a $6 \times$ C-terminal His tag, was amplified from genomic DNA. This amplicon was digested with $\mathrm{NcoI}$ and BamHI and cloned into the corresponding sites of the expression vector pET15b (Novagen). The resulting construct containing recombinant inuGA was designated pETInuGA-R. The stop codon in the recombinant gene was replaced with a codon for glutamate (CAA) by site-directed mutagenesis using primers LGstop-f and LG-stop-r and the Quick Change protocol (Stratagene) with pETInuGA-R as template (Supplementary Table S2). The resulting construct (pETInuGA-RM) with the recombinant mutant gene (inuGA-RM) was transformed into E. coli BL21 (DE3 Star) for expression.

Isolation of $\mathrm{ftf}$ genes from L. gasseri DSM 20604 and 20077 was initiated by PCR using the degenerate primers 5FTF and 6FTFi, which are based on conserved amino acid sequences of FTFs of Grampositive origin (van Hijum et al., 2002). Amplicons of 228 and 235 bp were amplified this way from the genomic DNA of $L$. gasseri DSM 20604 and L. 20077, respectively. These fragments were cloned in $E$. coli Top10 cells using the pCR-XL-TOPO vector and five individual clones were sequenced from each reaction. Isolation of the complete $\mathrm{ftf}$ genes was accomplished by standard and inverse PCR techniques (Supplementary Fig. S1) using the primers listed in supplementary Table S1.

The $\mathrm{ftf}$ genes of L. gasseri DSM 20604 and 20077 were designated inuGB and $\operatorname{lev} G$, respectively. For FTF protein expression, $5^{\prime}$ and $3^{\prime}$ truncated $i n u G B$ and $\operatorname{lev} G$ were amplified by PCR from genomic DNA 
using primer sets Lg604-F3/Lg604-R2 and Lg077-F2/Lg077-R2, respectively (Supplementary Table S2). These truncated $\mathrm{ftf}$ genes encode aa $137-703$ of the InuGB protein (designated InuGB-R) and aa 128-689 of the LevG protein (LevG-R), both containing $6 \times \mathrm{C}$ terminal His tags. These truncated genes were cloned into the expression vector pET15b using $\mathrm{NcoI}$ and BamHI restriction sites. The resulting vectors pETInuGB-R and pETLevG-R were transformed to E. coli BL21 (DE3 Star) for protein expression. Correct construction of the plasmids was confirmed by nucleotide sequence analysis (GATC).

Expression and purification of FTF proteins. Protein expression in overnight cultures $\left(600 \mathrm{ml}\right.$ each, grown at $37{ }^{\circ} \mathrm{C}$ in LB medium) of E. coli BL21 (DE3 star) harbouring pETInuGA-R, pETInuGA-RM, pETInuGB-R and pETLevG was induced with $0.1 \mathrm{mM}$ IPTG for $1 \mathrm{~h}$ at 200 r.p.m. The cells were harvested by centrifugation at $3500 \mathrm{~g}$ for 15 min and the FTF proteins were purified to homogeneity by NiNTA and anion-exchange chromatography as described by van Hijum et al. (2002).

\section{Biochemical characterization of the recombinant $L$. gasseri FTF enzymes.}

All enzyme assays were performed at $50{ }^{\circ} \mathrm{C}$ in $25 \mathrm{mM}$ sodium acetate buffer, $\mathrm{pH}$ 5.5, for InuGA-RM, pH 4.5, for InuGB-R and LevG-R, containing $1 \mathrm{mM} \mathrm{CaCl} 2$ and using $0.45 \mu \mathrm{g}$ protein $\mathrm{ml}^{-1}$ unless specified otherwise. Enzyme concentrations were determined using the Bradford reagent (Bio-Rad) with BSA as standard. One unit of enzyme activity is defined as the release of $1 \mu \mathrm{mol}$ monosaccharide $\min ^{-1}$ from sucrose. The enzyme activity was measured as the amount of glucose and fructose released from sucrose (van Hijum $e t$ al., 2001). The amount of glucose formed reflects the total amount of sucrose utilized during the reaction $\left(V_{\mathrm{G}}\right)$ (total activity). The amount of fructose $\left(V_{\mathrm{F}}\right)$ formed is a measure for the hydrolytic activity. The transglycosylation activity was calculated by subtracting the amount of free fructose from glucose $\left(V_{\mathrm{G}}-V_{\mathrm{F}}\right)$.

(i) Effect of $\mathrm{pH}$, temperature, $\mathrm{CaCl}_{2}$ and EDTA. Michaelis' barbital sodium acetate buffer (Chipperfield \& Taylor, 1970), pH 3.5-8.5 was used to study the effect of $\mathrm{pH}$ on the activity of recombinant FTF enzymes at $37{ }^{\circ} \mathrm{C}$, as described previously (Anwar et al., 2008). The effect of temperature on the enzyme activity was studied in $25 \mathrm{mM}$ sodium acetate buffer supplemented with $500 \mathrm{mM}$ sucrose and $1 \mathrm{mM}$ $\mathrm{CaCl}_{2}$. The effect on enzyme activity of scavenging calcium ions from the reaction buffer by EDTA $(0-1000 \mu \mathrm{M})$ was studied as described previously (Anwar et al., 2008).

(ii) Kinetic parameters. Kinetic parameters of the FTF reactions were determined by varying the sucrose concentration $(5-1000 \mathrm{mM})$ at 37 and $50{ }^{\circ} \mathrm{C}$. Data were fitted to the standard Michaelis-Menten formula: $V=\left(V_{\max }[S] /\left(K_{\mathrm{m}}+[S]\right)\right.$ using Sigma Plot (version 10.0), where $V$ is the specific activity $\left(\mathrm{U} \mathrm{mg}^{-1}\right), S$ is the substrate concentration ( $\mathrm{mM}$ sucrose), $V_{\max }$ is the maximum velocity ( $\mathrm{U}$ $\mathrm{mg}^{-1}$ ) and $K_{\mathrm{m}}$ is the Michaelis constant (mM sucrose).

Polysaccharide production and characterization. The polysaccharides synthesized by the three L. gasseri strains were produced by growing the strains anaerobically using a BBL gas pack in $100 \mathrm{ml}$ MRS-sucrose medium at $37^{\circ} \mathrm{C}$. After 5 days of incubation, the cultures were centrifuged at $4000 \mathrm{~g}$ for $10 \mathrm{~min}$ and the supernatants were separated from the cells. The supernatants $(3 \mu \mathrm{l}$ each) were analysed by TLC (Silica gel $60 \mathrm{~F}_{254}$; Merck). As mobile phase, 1butanol:ethanol: water $(5: 5: 3)$ was used and plates were run overnight. Plates were air-dried, sprayed with a urea developing solution specific for sugars containing fructose (Trujillo et al., 2004) and developed at $80{ }^{\circ} \mathrm{C}$. The polysaccharides were precipitated from the supernatant with 2 vols $96 \%$ cold ethanol followed by centrifugation at $2500 \mathrm{~g}$ for $15 \mathrm{~min}$. After dissolving in MilliQ water, the polymers were reprecipitated (Van Geel-Schutten et al., 1999). After repeating this process twice, the polymers were freeze-dried and the weights of these samples were measured. The three L. gasseri strains and $L$. reuteri 121 were also inoculated in MRS medium containing $500 \mathrm{mM}$ raffinose and incubated at $37{ }^{\circ} \mathrm{C}$ for 5 days; $3 \mu \mathrm{l}$ culture broth was analysed by TLC as described above.

For nuclear magnetic resonance (NMR) spectroscopy, the purified polymer products were dissolved in 99.9 atom $\% \mathrm{D}_{2} \mathrm{O}$ (SigmaAldrich). One-dimensional ${ }^{13} \mathrm{C}-\mathrm{NMR}$ spectra were recorded at $125 \mathrm{MHz}$ on a $500 \mathrm{MHz}$ Varian Inova NMR spectrometer at a probe temperature of $80{ }^{\circ} \mathrm{C}$. Chemical shifts are expressed in p.p.m. relative to the methyl group of internal acetone $(\delta=31.07)$. Carbon spectra were recorded in $38 \mathrm{~K}$ datasets, with a spectral width of $30166 \mathrm{kHz}$. Prior to Fourier transformation, the time-domain data were apodized with an exponential function, corresponding to a $0.5 \mathrm{~Hz}$ line broadening.

To study the product profile of the purified recombinant levan- and inulosucrases of the L. gasseri strains, the enzymes $\left(100 \mathrm{U} \mathrm{l}^{-1}\right)$ were incubated at $37{ }^{\circ} \mathrm{C}$ with sucrose $(600 \mathrm{mM})$ for $72 \mathrm{~h}$ in $25 \mathrm{mM}$ sodium acetate buffer $\mathrm{pH} 4.5$ (for InuGB-R and LevG-R) and $\mathrm{pH} 5.5$ (for InuGA-RM) containing $1 \mathrm{mM} \mathrm{CaCl}_{2}$. To analyse product formation, $1 \mu \mathrm{l}$ aliquots from these reaction mixtures $(4 \times$ diluted $)$ were run on TLC plates overnight. Activities of these enzymes were also tested on raffinose $(500 \mathrm{mM})$ using the same $\mathrm{pH}$ and temperature conditions, but with $5000 \mathrm{U}^{-1}$ enzyme concentration and $18 \mathrm{~h}$ incubation time. Recombinant L. reuteri 121 inulosucrase (Inu_699His) (van Hijum et al., 2002) was used as a positive control.

High-pressure anion-exchange (HPAE) chromatography (Dionex) was used to separate oligosaccharides produced by growing (for 5 days) cultures of L. gasseri strains DSM 20604 and 20077, and incubating InuGA-RM with sucrose for $72 \mathrm{~h}$ at $37{ }^{\circ} \mathrm{C}$, as described above. Separation of these fructo-oligosaccharides (FOS) was achieved as described previously (Ozimek et al., 2006a) using the following gradient (with eluent B): eluent A (0 min, $100 \%)$; (10 min, $78 \%$ ); (25 min, $60 \%)$; $(80 \mathrm{~min}, 10 \%)$; (83 min, $0 \%)$; (91 min, $100 \%$ ). Eluent $\mathrm{A}$ was $0.1 \mathrm{M}$ sodium hydroxide and eluent $\mathrm{B}$ was $0.1 \mathrm{M}$ sodium hydroxide in $0.6 \mathrm{M}$ sodium acetate. As standards, a 1:1 mixture of Raftiline ST-Gel and Raftiline HP (Orafti) representing chicory inulin were used.

Quantitative analysis of the products synthesized by the FTF enzymes. For quantitative analysis of the FOS and polymers synthesized, the enzymes were incubated under similar conditions to those described above and the enzyme activity was monitored by determining the glucose released from sucrose after every $24 \mathrm{~h}$. After 7 days of incubation, when glucose concentration did not further increase, $0.1 \mathrm{ml}$ sample aliquots were taken and subjected to analysis by HPAE (see below). The remaining part of the reaction mixture was treated with 2 vols cold ethanol for polymer isolation and purification, as described above. Fructan polymer solutions $(1 \% \mathrm{w} /$ v) were prepared in demineralized water by heating at $50{ }^{\circ} \mathrm{C}$ for $10 \mathrm{~min}$. For complete degradation, the inulin solutions $(100 \mu \mathrm{l})$ were incubated for $4 \mathrm{~h}$ in $100 \mathrm{mM}$ acetate buffer at $\mathrm{pH} 4.5(100 \mu \mathrm{l})$ with 20 units exo-inulinase (Megazyme) and 1 unit endo-inulinase (Megazyme) to a total volume of $300 \mu \mathrm{l}$ with MilliQ water. Similarly, the levan was treated with 5 units endo-inulinase and 20 units inulinase of Aspergillus niger (Fluka) for $48 \mathrm{~h}$ under sterile conditions. After complete degradation, the fructose concentration of the samples was determined.

HPAE chromatography (see above) was used to quantitatively determine the remaining sucrose, and the glucose and fructose produced by the purified recombinant enzymes. The amount of free glucose $\left(G_{f}\right)$ produced is a measure of total FTF activity, which 
includes hydrolysis and transglycosylation reactions. Subtracting the amount of free fructose $\left(\mathrm{F}_{\mathrm{f}}\right)$, produced as a result of hydrolytic activity, from that of free glucose $\left(G_{f}\right)$ gave the amount of fructose $\left(\mathrm{F}_{\mathrm{t}}\right)$ involved in transglycosylation reactions $\left(\mathrm{F}_{\mathrm{t}}=\mathrm{G}_{\mathrm{f}}-\mathrm{F}_{\mathrm{f}}\right)$. The amount of fructan polymer was determined by weight (see above) and its fructose content $(\mathrm{Fp})$ was determined as described above. The fructose incorporated in FOS $\left(\mathrm{F}_{\text {fos }}\right)$ is defined as the difference between the amount of fructose $\left(\mathrm{F}_{\mathrm{t}}\right)$ involved in transglycosylation reactions and fructose $\left(\mathrm{F}_{\mathrm{p}}\right)$ incorporated into the polymer product $\left(\mathrm{F}_{\text {fos }}=\mathrm{F}_{\mathrm{t}}-\mathrm{F}_{\mathrm{p}}\right)$. It is worth mentioning that, in our studies, the values for the amount of fructose incorporated in the polymer product are likely to be slightly underestimated due to small losses of the product during purification steps, with a concomitant overestimation of the fructose in FOS that was calculated indirectly (see above). However, the results still allow a comparative analysis.

Enzyme localization studies. L. gasseri strains were grown in MRS medium with $30 \mathrm{~g}$ sucrose $1^{-1}$ at $37{ }^{\circ} \mathrm{C}$ and the cultures were diluted with MRS medium to $\mathrm{OD}_{600}=1.0$ before being harvested by centrifugation ( $10000 \mathrm{~g}$ for $15 \mathrm{~min}$ ) in the late exponential growth phase. Cells were washed twice with saline solution $\left(8.5 \mathrm{~g} \mathrm{l}^{-1}\right)$ and resuspended to the original volume in $25 \mathrm{mM}$ sodium acetate buffer ( $\mathrm{pH}$ 5.5) containing $1 \mathrm{mM} \mathrm{CaCl}_{2}$. Culture supernatants were dialysed for $24 \mathrm{~h}$ against this sodium acetate buffer, which was replaced four times during dialysis. Total, hydrolysis and transglycosylation activities in the washed cells and supernatants were measured as described previously (Anwar et al., 2008) at $37^{\circ} \mathrm{C}$ in $25 \mathrm{mM}$ sodium acetate buffer, $\mathrm{pH} 5.5$, containing $1 \mathrm{mM} \mathrm{CaCl}_{2}$, using $62 \mu \mathrm{l}$ cell suspension or supernatant in the reaction mixture as the source of enzyme. Sucrose was used as substrate at $500 \mathrm{mM}$ final concentration.

\section{RESULTS AND DISCUSSION}

\section{Isolation and nucleotide sequence analysis of three putative $L$. gasseri ftf genes}

Previous work (Pridmore et al., 2004; van Hijum et al., 2006) suggested that the genome of L. gasseri DSM 20243 contains a putative $\mathrm{ftf}$ gene. Supplementary material related to the published genome sequence of DSM 20243 (Azcarate-Peril et al., 2008) indicated the presence of two gene loci, LGAS_1281 and LGAS_1282, with assigned functions in fructan synthesis. However, analysis of the genome sequence (GenBank accession no. CP000413) revealed that the genes with these identities have no similarity with $\mathrm{ftf}$ genes. Instead, a locus tag, LGAS_1266, annotated as a pseudogene, shows high similarity to the inulosucrase (inuJ, orf LJ0913; GenBank accession no. AE017198) of L. johnsonii NCC 533 (Anwar et al., 2008; Pridmore et al., 2004). The complement of this gene spans the region 1262127-1264493 bp of the L. gasseri DSM 20243 genome.

Molecular analysis showed that this putative $\mathrm{ftf}$ gene was terminated by a stop codon (TAA), 4 aa before the end of the catalytic domain, whereas all other lactobacilli $\mathrm{ft} f$ genes possess a glutamine codon (CAA) at this position. Cloning and subsequent exchange of the stop codon with the glutamine codon resulted in an $\mathrm{ftf}$ gene (inuGA) encoding an inulosucrase enzyme with similar domain organization and size as the previously described fructansucrases of lactobacilli (Fig. 1). It is interesting to note that strain $L$. gasseri DSM 20243 contains a heteropolysaccharide biosynthesis gene cluster (LGAS_1156 to LGAS_1172) composed of 16 genes (Azcarate-Peril et al., 2008), in addition to the $\mathrm{ftf}$ gene. To our knowledge, this is the first example of both an $\mathrm{ftf}$ gene (homopolysaccharide) and a heteropolysaccharide gene cluster in a single bacterium.

The $\mathrm{ftf}$ genes from L. gasseri strains DSM 20604 and DSM 20077, of which the genome sequences are unknown, were obtained as described previously (van Hijum et al., 2002, 2004; Waldherr et al., 2008), using degenerate and specific primers. Consequently, a 2707 bp DNA fragment containing an FTF open reading frame of 2283 bp (inuGB) was sequenced from the genomic DNA of L. gasseri DSM 20604 (Supplementary Fig. S1a). Similarly, a 2960 bp DNA fragment containing a single FTF open reading frame of 2304 bp $(\operatorname{lev} G)$ was obtained from the genomic DNA of $L$. gasseri DSM 20077 (Supplementary Fig. S1b). Sequence analysis of the genes confirmed their $\mathrm{ftf}$ identities. Sequencing of five separate clones from each strain, obtained with the degenerate primers 5FTF and 6FTFi, yielded identical sequences, indicating that each strain contains a unique single $\mathrm{ft} f$ gene. The putative inulosucrase protein InuGB has a deduced molecular mass of $83 \mathrm{kDa}$

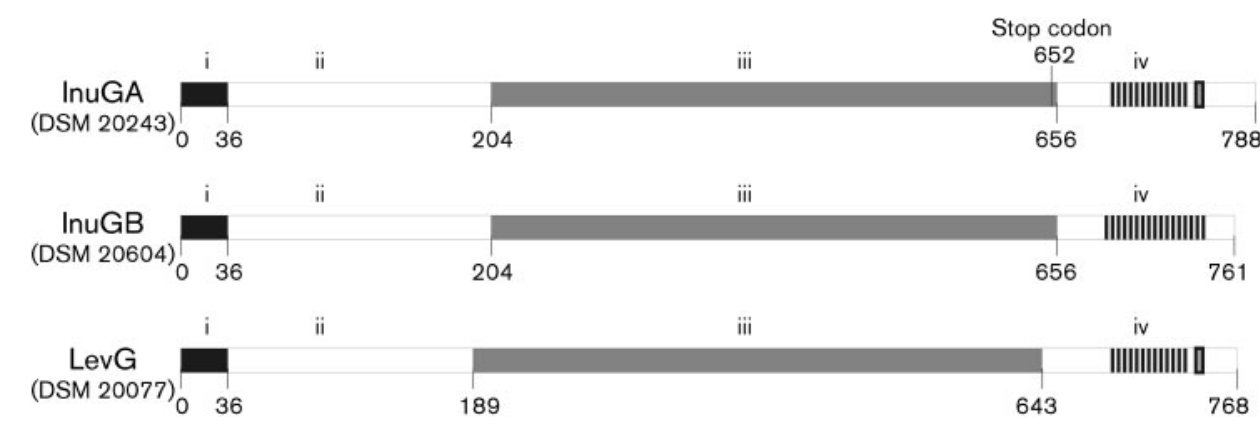

Fig. 1. Schematic representation of the domain organization of FTF enzymes of $L$. gasseri strains showing four different protein domains: (i) signal sequence, (ii) N-terminal variable region, (iii) catalytic domain, (iv) C-terminal domain with PXX repeats (black hatched boxes) and cell-wall-anchoring LPKAG motifs (grey boxes surrounded by a thick black line). 
and $\mathrm{pI}$ of 5.44, while the putative levansucrase protein LevG has a deduced molecular mass of $84 \mathrm{kDa}$ and $\mathrm{pI}$ of 5.22 .

\section{Amino acid sequence analysis of the three isolated FTFs}

Alignments of the full-length amino acid sequence of InuGA with other fructosyltransferases revealed that it had the highest similarity with the inulosucrase (InuJ) of $L$. johnsonii NCC 533 (81\% identity) (Anwar et al., 2008). The amino acid sequence of LevG exhibited the highest similarity with L. johnsonii NCC 533 InuJ inulosucrase (59\% identity) and InuGA (58\% identity). Among other levansucrases, LevG showed the highest similarity to $L$. reuteri 121 (50\% identity) (van Hijum et al., 2004) and $L$. sanfranciscensis ( $49 \%$ identity) (Tieking et al., 2005) levansucrases. Similarly, InuGB had the highest similarity (86\% identity) with InuGA. However, a major difference between these two proteins is the preliminary stop codon in the latter, as already mentioned above.

Analysis of the deduced FTF amino acid sequences encoded by the three FTFs revealed the presence of: (i) a signal peptide, (ii) an N-terminal variable region, (iii) a catalytic domain and (iv) a C-terminal domain (Fig. 1).

(i) Signal peptides and $\mathrm{N}$-terminal variable regions.

As predicted by SignalP, all three FTFs possess a typical Gram-positive signal peptide of 36 aa for secretion (Fig. 1), in agreement with the extracellular location of FTF enzymes. The N-terminal variable regions of these $L$. gasseri FTFs were similar in size to FTFs from other lactobacilli, ranging from 152 to 167 aa (Fig. 1). Including the InuGA, InuGB and LevG sequences, the amino acid sequence of the FTF $\mathrm{N}$-terminal region is clearly variable among the FTFs of lactobacilli (not shown).

\section{(ii) Catalytic domains.}

The catalytic domains of the three L. gasseri FTF enzymes are very similar in size, approximately 450 aa (Fig. 1), corresponding very well to the sizes observed in other lactobacilli FTF enzymes. The amino acids reported to be involved in catalysis (Homann et al., 2007; Meng \& Futterer, 2003; Ozimek et al., 2004) are conserved in the catalytic cores of the L. gasseri FTFs, and correspond to D266, D419 and E518 in InuGA; D257, D410 and E509 in InuGB; and D251, D404 and E505 in LevG.

\section{(iii) C-terminal domains.}

The $\mathrm{C}$ terminus of InuGA contains an amino acid sequence with a 13-fold repeat of the motif PXX, a Gram-positive cell wall anchoring domain of 41 aa (from aa 744 to 784 ) containing an LPKAG motif and a hydrophobic stretch of 23 aa (from aa 760 to 782 ). A C-terminal variable region of 43 aa is present between the catalytic core and the cell wall anchoring domain and the protein is terminated by six positively charged amino acids (Fig. 1). The LPKAG motif was also reported to occur in L. johnsonii NCC 533 inulosucrase InuJ (Anwar et al., 2008) and is similar to the consensus sequence LPXTG, which is well-conserved in Gram-positive cell-wall-associated proteins (Fischetti et al., 1990; van Hijum et al., 2002, 2004; Waldherr et al., 2008). The $\mathrm{C}$ terminus of InuGB contains a 17 -fold repeat of the motif PXX preceded by a C-terminal variable region of 43 aa. The protein terminated abruptly at aa 761 and it lacked the cell-wall-anchoring LPXTG/LPKAG motif. In LevG, a proline-rich spacer region of 82 aa with a 13-fold repeat of the motif PXX was present following the catalytic core. A Gram-positive anchor spanned from aa 724 to 764 on the $\mathrm{C}$ terminus of LevG and contained the cell-wall-anchoring motif LPKAG.

\section{Expression of recombinant ftf genes in E. coli}

Based on the obtained sequences, the three $\mathrm{ft} f$ genes were cloned and successfully expressed in E. coli. To enable high level protein expression in E. coli, truncated versions of the L. gasseri ftf genes were made in accordance with the strategies used in previous studies (Anwar et al., 2008; Tieking et al., 2005; van Hijum et al., 2002), where the truncations did not affect enzyme activity and the composition of the polysaccharide products. The recombinant InuGA-RM contained a glutamine residue instead of the stop codon. Attempts to express the native sequence with the stop codon yielded only inclusion bodies that could not be solubilized. Purified proteins of $\sim 63 \mathrm{kDa}$ each were obtained from all the constructs and subjected to further characterization.

\section{Biochemical characterization of the recombinant FTF enzymes of $\boldsymbol{L}$. gasseri}

(i) Effect of $\mathrm{pH}$, temperature and $\mathrm{CaCl}_{2}$ on enzyme activity. The effect of $\mathrm{pH}$ on the FTF enzyme activities was studied at $37{ }^{\circ} \mathrm{C}$. The highest total inulosucrase activity of InuGA$\mathrm{RM}$ was observed in the $\mathrm{pH}$ range from 4.5 to 6.0 , with maximum activity between $\mathrm{pH} 4.5$ and 5.5. This enzyme exhibited highest activity at $50{ }^{\circ} \mathrm{C}$. Both the LevG-R and InuGB-R exhibited the highest activities in a relatively lower $\mathrm{pH}$ range, i.e. at $\mathrm{pH} 3.5-4.5$, and at a temperature of $55{ }^{\circ} \mathrm{C}$, with a drastic activity decrease at $60{ }^{\circ} \mathrm{C}$.

The pH optima of LevG-R and InuGB-R are relatively low compared with those of several other FTF enzymes. For instance, the levansucrase of $L$. sanfranciscensis has an optimum $\mathrm{pH}$ of 5.4 (Tieking et al., 2005) and the FTF enzymes of $L$. reuteri display an optimum range of $\mathrm{pH} 4.5$ 5.5 (van Hijum et al., 2003, 2004). In contrast, levansucrase from $L$. mesenteroides exhibited highest activity at $\mathrm{pH}$ 6.5-7 (Olvera et al., 2007), while the inulosucrase of L. johnsonii NCC 533 exhibited maximum transglycosylation activity in two $\mathrm{pH}$ regions, $\mathrm{pH} 4.5-6.0$ and at $\mathrm{pH}$ 7.0, and maximum hydrolytic activity at pH 7.0 (Anwar et al., 2008). Optimal enzymic activity for levansucrase of $L$. panis (Waldherr et al., 2008) was observed in the $\mathrm{pH}$ range $4-4.6$, which is 
almost the same as those of InuGB-R and LevG-R (this study). Higher optimum temperatures for activity have also been reported for the FTF enzymes from $L$. reuteri $\left(50{ }^{\circ} \mathrm{C}\right)$ (van Hijum et al., 2003, 2004), L. sanfranciscensis $\left(35-45{ }^{\circ} \mathrm{C}\right)$ (Tieking et al., 2005), Bacillus sp. $\left(60^{\circ} \mathrm{C}\right)$ (Ben Ammar et al., 2002) and L. panis $\left(45-50{ }^{\circ} \mathrm{C}\right)$ (Waldherr et al., 2008).

Enzyme activity of InuGA-RM was most adversely affected by addition of EDTA in the reaction mixture, reaching a $92 \%$ reduction at $800 \mu \mathrm{M}$ EDTA. By comparison, EDTA less strongly affected the InuGB-R and LevG-R activity, causing a 30 and $48 \%$ drop in activity, respectively, at $800 \mu \mathrm{M}$ EDTA. Enzyme activities remained unaffected when $400 \mu \mathrm{M} \mathrm{Ca}^{2+}$ ions was added in the presence of $800 \mu \mathrm{M}$ EDTA. These results indicated that calcium ions are required for optimal activity of the L. gasseri FTF enzymes, in agreement with the proven role of calcium ions for stability in other FTF enzymes. Using site-directed mutagenesis, Ozimek et al. (2005) demonstrated that Asp520 in inulosucrase of $L$. reuteri 121 plays an important role in $\mathrm{Ca}^{2+}$ binding. The equivalent amino acid residues in L. gasseri InuGA, InuGB and LevG are Asp515, 506 and 505, respectively. This Asp residue is highly conserved in family GH68 proteins of Gram-positive origin.

\section{(ii) Kinetic parameters.}

Kinetic parameters for the FTF enzyme activities were determined at 37 and $50{ }^{\circ} \mathrm{C}$ (Table 1). However, at both temperatures, the kinetic constants could not be determined for the total $\left(V_{\mathrm{G}}\right)$ and transglycosylation $\left(V_{\mathrm{G}-\mathrm{F}}\right)$ activities of InuGA-RM and InuG-R, because these enzymes did not become saturated at the higher sucrose concentrations. Consequently, high standard errors were obtained with curve fits.

The non-Michaelis-Menten kinetic behaviour exhibited by InuGA-RM and InuGB-R was similar to that reported for inulosucrases of L. reuteri 121 (van Hijum et al., 2002) and L. johnsonii NCC 533 (Anwar et al., 2008). This typical behaviour has been attributed to the oligosaccharides that were formed at an early stage of the reaction that might act as better acceptor substrates than the growing polymer chain (Anwar et al., 2008). In spite of its high similarity ( $86 \%$ identity) with InuGA-RM, InuGB-R exhibited significantly higher total and transglycosylation enzyme activities (Table 1).

All three enzymes exhibited higher total FTF activity values at $50{ }^{\circ} \mathrm{C}$ compared with $37^{\circ} \mathrm{C}$. The $K_{\mathrm{m}}$ and $k_{\text {cat }}$ values were also higher at $50{ }^{\circ} \mathrm{C}$. For InuGA-RM and LevG-R, the transglycosylation/hydrolysis ratios remained almost constant when the temperature was increased to $50{ }^{\circ} \mathrm{C}$. However, LevG-R was highly hydrolytic at both temperatures with relatively low $k_{\text {cat }}$ values for transglycosylation activity. Its $K_{\mathrm{m}}$ value for hydrolysis at $37{ }^{\circ} \mathrm{C}$ is comparable to that of the levansucrase of $B$. megaterium (Homann et al., 2007). At $37^{\circ} \mathrm{C}$, InuGB-R exhibited about three times higher transglycosylation activity than hydrolysis, with a 1.3 -fold increase at $50{ }^{\circ} \mathrm{C}$.

\section{Production and identification of the polymer products}

The oligo- and polysaccharide products synthesized during growth of L. gasseri DSM 20604 and DSM 20077 cultures,

Table 1. FTF activities [U (mg protein $\left.)^{-1}\right]$ and apparent kinetic constants for the L. gasseri FTF enzymes

The kinetic constants are $K_{\mathrm{m}}(\mathrm{mM})$ and $k_{\text {cat }}\left(\mathrm{s}^{-1}\right)$ for formation of glucose ( ${ }^{\mathrm{G}}$; total enzyme activity), formation of fructose $\left({ }^{\mathrm{F}}\right.$; hydrolytic enzyme activity) and glucose minus fructose ( ${ }^{\mathrm{G}-\mathrm{F}}$; transglycosylation enzyme activity). ND, Kinetic parameters could not be determined due to the fact that these enzymes did not become saturated with sucrose, resulting in high standard errors with curve fits. Values indicated are means \pm SD of the results from two independent experiments.

\begin{tabular}{|c|c|c|c|c|c|c|}
\hline \multirow[t]{2}{*}{ Kinetic parameters } & \multicolumn{2}{|c|}{ InuGA-RM } & \multicolumn{2}{|c|}{ InuGB-R } & \multicolumn{2}{|c|}{ LevG-R } \\
\hline & $37^{\circ} \mathrm{C}^{\star}$ & $50{ }^{\circ} \mathrm{C} \dagger$ & $37^{\circ} \mathrm{C} \ddagger$ & $50{ }^{\circ} \mathrm{C} \ddagger$ & $37^{\circ} \mathrm{C} \neq$ & $50{ }^{\circ} \mathrm{C} \ddagger$ \\
\hline Transglycosylation $\S$ & $189 \pm 11.3$ & $243 \pm 19.1$ & $291 \pm 3.5$ & $430 \pm 8.5$ & $43 \pm 0.7$ & $50 \pm 0.7$ \\
\hline Hydrolysis $\$$ & $127 \pm 21.2$ & $168 \pm 2.1$ & $88 \pm 4.9$ & $108 \pm 13.4$ & $195 \pm 19.8$ & $230 \pm 1.4$ \\
\hline Transglycosylation/hydrolysis $§$ & 1.5 & 1.5 & 3.0 & 4.0 & 0.2 & 0.2 \\
\hline$K_{\mathrm{m}}^{\mathrm{F}}$ & $4.8 \pm 1.0$ & $5.8 \pm 0.9$ & $14.7 \pm 4.3$ & $9.4 \pm 1.5$ & $7.3 \pm 1.5$ & $8.3 \pm 1.0$ \\
\hline$k_{\mathrm{cat}}^{\mathrm{F}}$ & $133 \pm 22.3$ & $177 \pm 2.2$ & $92 \pm 5.2$ & $113 \pm 14.1$ & $204 \pm 20.8$ & $242 \pm 0.7$ \\
\hline$K_{\mathrm{m}}^{\mathrm{G}-\mathrm{F}}$ & $\mathrm{ND}$ & $\overline{\mathrm{ND}}$ & $\mathrm{ND}$ & $\mathrm{ND}$ & $3.2 \pm 1.2$ & $6.9 \pm 1.6$ \\
\hline$k_{\mathrm{cat}}^{\mathrm{G}} \mathrm{G}$ & ND & ND & ND & ND & $45 \pm 0.7$ & $53 \pm 1.5$ \\
\hline
\end{tabular}

${ }^{\star}$ Enzyme assays were carried out with $0.55 \mu \mathrm{g} \mathrm{m}{ }^{-1}$ enzyme (final concentration). $\dagger$ Enzyme assays were carried out with $0.25 \mu \mathrm{g} \mathrm{ml}^{-1}$ enzyme (final concentration). ‡Enzyme assays were carried out with $0.45 \mu \mathrm{g} \mathrm{ml}^{-1}$ enzyme (final concentration). $\$$ Activity values measured at $500 \mathrm{mM}$ sucrose. 
and the purified recombinant InuGA-RM enzyme, with sucrose or raffinose at $37{ }^{\circ} \mathrm{C}$ for 5 days, were analysed by TLC. The TLC pattern showed that InuGA-RM and $L$. gasseri DSM 20604 convert sucrose into a range of FOS in addition to polymeric material (Fig. 2). ${ }^{13} \mathrm{C}$ NMR spectra of the polysaccharides produced by InuGA-RM, the growing culture of L. gasseri DSM 20604 and its recombinant enzyme InuGB-R, revealed the presence of $\beta 2-1$ linkages only, thus identifying the fructan formed as an inulin (Supplementary Fig. S2a; Table 2) (Anwar et al., 2008; Morales-Arrieta et al., 2006; Olivares-Illana et al., 2002; Shimamura et al., 1987; van Hijum et al., 2001). L. gasseri 20077, in contrast, produced a fructan of the levan type, as revealed by ${ }^{13} \mathrm{C}$ NMR spectroscopy of the purified polysaccharide product (Supplementary Fig S2b; Table 2). L. gasseri 20243 did not produce any FOS or polymer product in spite of its growth on MRS medium containing sucrose.

HPAEC analysis showed that the FOS produced by $L$. gasseri 20604 and the InuGA-RM enzyme was of the inulintype, and oligosaccharides ranging from GF2 to GF13 were clearly detected on the chromatogram (Fig. $3 \mathrm{a}$ and c). In contrast, L. gasseri DSM 20077 synthesized a polymer product and kestose only (Fig. 2 and Fig. $3 \mathrm{~b}$ ). In a recent report (Azcarate-Peril et al., 2008), none of the nine $L$. gasseri strains tested, including the type strain (DSM 20243), was found to ferment raffinose. We also could not detect any growth or product formation by the three $L$. gasseri strains used in our studies, not even after 5 days of incubation with $500 \mathrm{mM}$ raffinose (Fig. 4a). However, all three strains showed copious growth on MRS-raffinose medium supplemented with $50 \mathrm{mM}$ sucrose, indicating that the growth was not inhibited by raffinose.

Also, the recombinant purified L. gasseri inulosucrases InuGA-RM and InuGB-R produced inulin polymer and FOS (data not shown), with similar TLC patterns to those observed for the products of whole cells of the respective strains. These TLC patterns were similar to those observed

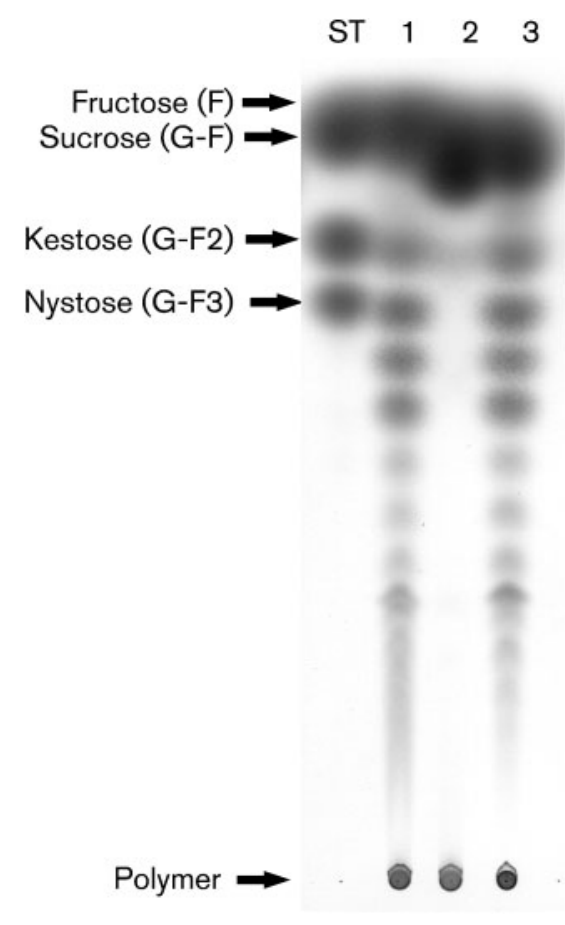

Fig. 2. TLC analysis of oligo/polysaccharides produced by $L$. gasseri strains DSM 20604 (1) and DSM 20077 (2), and by the recombinant purified InuGA-RM enzyme from $L$. gasseri DSM 20243 (3). ST, Sucrose, kestose and nystose standards.

for the L. reuteri 121 Inu products (Ozimek et al., 2006b), but were clearly different from those of the L. johnsonii NC533 InuJ products (Anwar et al., 2008), due to the absence of the unidentified product spot observed for the latter between the sucrose and kestose spots. Moreover, HPAEC chromatograms of InuGA-RM and InuGB-R FOS products exhibited single peaks, whereas double peaks were observed for InuJ products (Anwar et al., 2008). The data

Table 2. ${ }^{13} \mathrm{C}$ NMR chemical shift values of fructans produced by Lactobacillus strains (S) and recombinant FTF enzymes (R)

\begin{tabular}{|c|c|c|c|c|c|c|c|c|c|}
\hline \multirow[t]{2}{*}{$\begin{array}{l}\text { Carbon } \\
\text { atom }\end{array}$} & \multicolumn{2}{|c|}{ Levan L. reuteri $121^{\star}$} & \multicolumn{2}{|c|}{$\begin{array}{c}\text { Inulin } L . \text { johnsonii NCC } \\
533 \dagger\end{array}$} & \multicolumn{2}{|c|}{$\begin{array}{c}\text { Levan L. gasseri DSM } \\
20077\end{array}$} & \multirow{2}{*}{$\begin{array}{c}\text { Inulin } L . \\
\text { gasseri } \\
\text { DSM } \\
20243 \\
\text { R }\end{array}$} & \multicolumn{2}{|c|}{$\begin{array}{c}\text { Inulin L. gasseri DSM } \\
20604\end{array}$} \\
\hline & $S$ & $\mathbf{R}$ & $S$ & $\mathbf{R}$ & $S$ & $\mathbf{R}$ & & $S$ & $\mathbf{R}$ \\
\hline C-1 & 61.7 & 59.6 & 62.1 & 62.2 & 61.7 & 61.6 & 62.0 & 62.1 & 62.1 \\
\hline C-2 & 105.0 & 104.0 & 104.1 & 104.2 & 105.1 & 105.1 & 104.1 & 104.1 & 104.1 \\
\hline C-3 & 78.1 & 76.0 & 78.3 & 78.4 & 78.0 & 77.9 & 78.2 & 78.2 & 78.3 \\
\hline C-4 & 76.6 & 74.9 & 75.6 & 75.6 & 76.6 & 76.5 & 75.6 & 75.6 & 75.6 \\
\hline C-5 & 81.2 & 80.0 & 82.2 & 82.2 & 81.3 & 81.2 & 82.1 & 82.1 & 82.1 \\
\hline C-6 & 64.3 & 63.2 & 63.2 & 63.1 & 64.3 & 64.3 & 63.1 & 63.1 & 63.1 \\
\hline
\end{tabular}

*van Hijum et al. (2001).

$\dagger$ Anwar et al. (2008). 

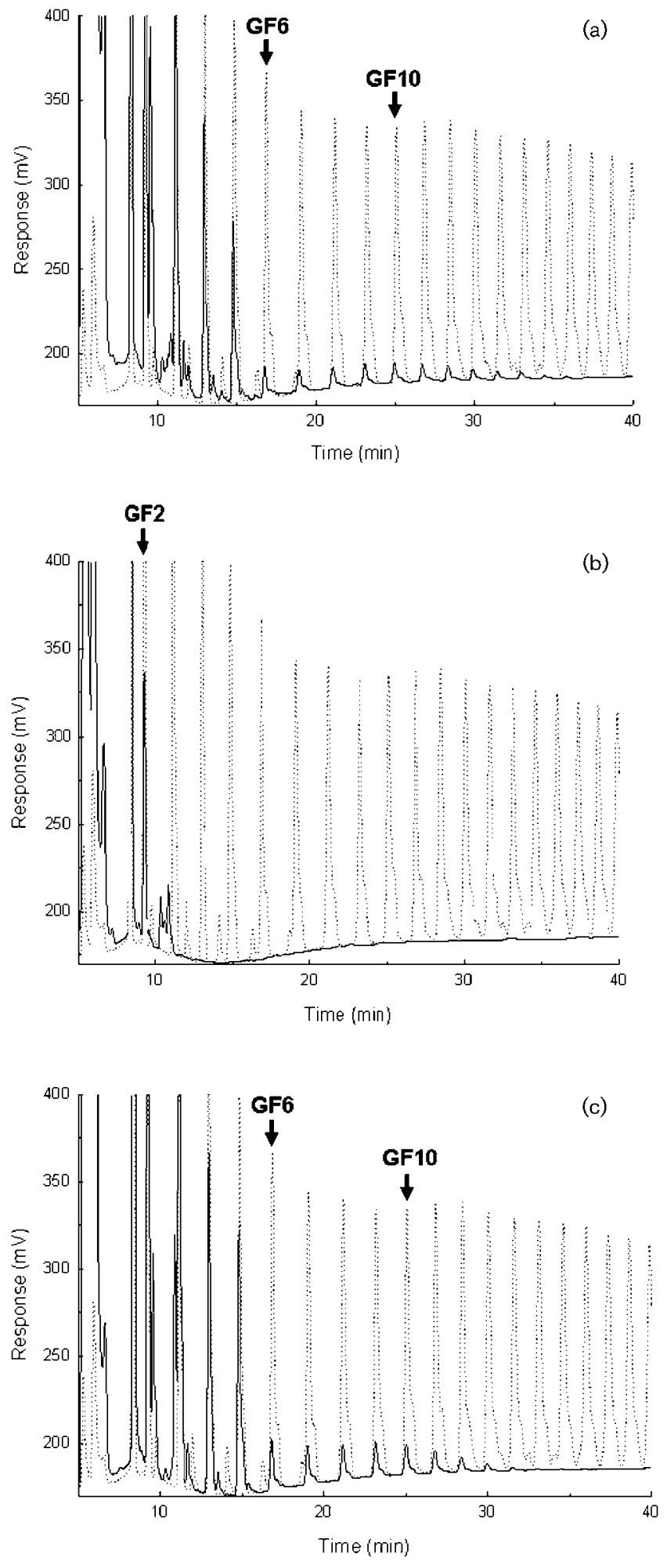

Fig. 3. HPAE chromatography analysis of the FOS products synthesized by L. gasseri strains DSM 20604 (a) and DSM 20077 (b) in situ, and by the purified recombinant InuGA-RM (c) enzyme. Dotted lines, inulin standards, a 1:1 mixture of Raftiline ST-Gel and Raftiline HP representing chicory inulin. reported here for the L. gasseri strains DSM20604 and DSM20077, and the purified recombinant InuGA-RM, InuGB-R and LevG-R enzymes, also provide further evidence that inulosucrase, but not levansucrase, enzymes of lactobacilli synthesize a range of FOS molecules, in addition to the inulin polymer (Fig. 2). The broad range of inulin-type FOS synthesis by the growing culture of $L$. gasseri DSM 20604 (and by the InuGB-R enzyme) has never been reported for any other bacteria (and inulosucrase enzymes). These results thus reveal interesting variations in the composition of FOS synthesized by the recombinant inulosucrases of various lactobacilli. Although none of the three L. gasseri strains was able to ferment raffinose, their respective recombinant enzymes were clearly active with raffinose as a substrate. The enzymes InuGA-RM and InuGB-R converted raffinose into a polymer and into FOS with a TLC pattern comparable to that of L. reuteri Inu $\Delta 699 \mathrm{His}$, whereas LevG-R produced a polymer and a single oligosaccharide (most likely Gal-GlcFrc-Frc) (Fig. 4b). It remains unclear why the L. gasseri and L. reuteri 121 strains differ in their ability to grow on raffinose.

\section{Quantitative analysis of the products synthesized by the FTF enzymes}

After 7 days of incubation with $600 \mathrm{mM}$ sucrose at $37{ }^{\circ} \mathrm{C}$, equal units $\left(100 \mathrm{U} \mathrm{l}^{-1}\right)$ of the InuGA-RM, InuGB-R and LevG-R produced $11.0 \pm 1.6 \mathrm{~g} \mathrm{l}^{-1}, 13.0 \pm 0.5 \mathrm{~g} \mathrm{l}^{-1}$ and $15.0 \pm 0.4 \mathrm{~g} \mathrm{l}^{-1}$ of the fructan polysaccharide product, respectively. These values were significantly higher than those reported for $L$. reuteri 121 Inu and Lev, which produced $0.8 \mathrm{~g} \mathrm{l}^{-1}$ and $1.4 \mathrm{~g} \mathrm{l}^{-1}$ polymers, respectively (van Hijum et al., 2001, 2002). However, it is noteworthy that lower sucrose and enzyme concentrations were used and less incubation time was given in the L. reuteri 121 studies. Our HPAEC data (Table 3) revealed that the maximum amount of added sucrose was consumed by InuGB-R, of which the major portion was integrated into FOS, while about $20 \pm 1.8 \mathrm{~g} \mathrm{l}^{-1}$ of fructose was incorporated into the inulin polymer product. A similar trend was observed for InuGA-RM, where $41 \pm 2.9 \mathrm{~g} \mathrm{l}^{-1}$ of fructose was incorporated into FOS. FOS production was also the dominant reaction of $L$. reuteri 121 Inu (van Hijum et al., 2002), constituting about $86 \%$ of the transglycosylation reaction. The levansucrase, LevG-R, consumed about $66 \%$ of the total sucrose, with the major part being hydrolysed and about $22 \pm 0.9 \mathrm{~g} \mathrm{l}^{-1}$ of fructose incorporated into polysaccharide product. The extent of sucrose hydrolysis (determined as free fructose) for LevG-R is about 2.0-2.5 times higher than that for InuGA-RM and InuGB-R (Table 3 ). Higher hydrolytic activity (51.6\% of sucrose consumed) has also been reported for L. reuteri $121 \mathrm{Lev}$, which is about three times higher than the hydrolytic activity exhibited by inulosucrase of the same strain (at a sucrose concentration of $840 \mathrm{mM}$ ) (Ozimek et al., 2006b). On the contrary, levansucrase of $L$. panis yielded higher amounts of fructan and kestose, indicating predominant transgly- 


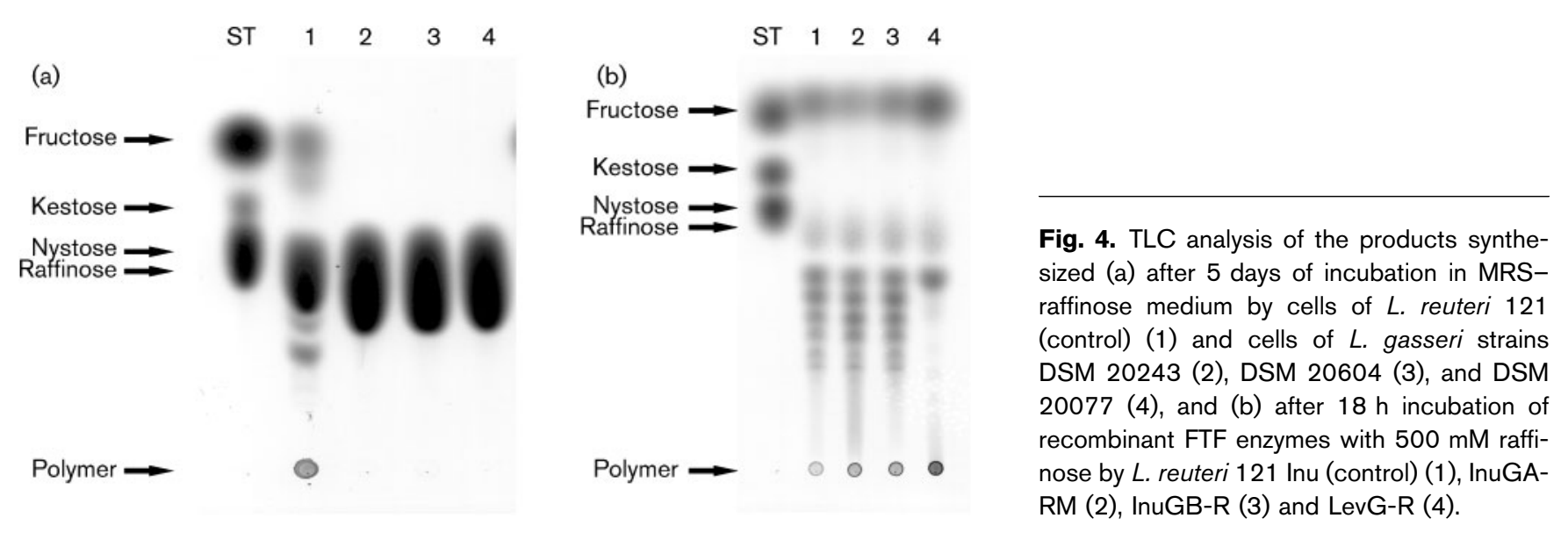

cosylation reaction at $500 \mathrm{mM}$ sucrose concentration (Waldherr et al., 2008). Studies with truncated versions of L. sanfranciscensis levansucrase, Lev $\Delta \mathrm{His}$ and LevCD $\Delta$ His, have shown that environmental conditions affect product ratios, with low temperature and high sucrose concentration favouring production of kestose (Tieking et al., 2005). Nonetheless, significantly high amounts of free fructose were produced in all incubations with these Lev enzymes, indicating high hydrolytic activity. The differences in transglycosylation/hydrolysis activities of levan- and inulosucrase enzymes also indicate that these enzymes diverge at the structural level.

\section{Enzyme localization studies}

The LPXTG/LPKAG motifs are known as cell-wall-anchoring motifs for proteins in many bacteria. Presence of an incomplete cell-wall-anchoring domain and lack of the LPXTG/LPKAG motif raised questions about the cellular location of the L. gasseri 20604 inulosucrase protein. The impact was clearly indicated by the tendency of the enzyme to be secreted into the growth medium in contrast with the L. gasseri 20077 levansucrase, which was exclusively detected associated with the cell surface (Table 4).

Washed cell suspensions and dialysed culture supernatants of L. gasseri DSM 20604 exhibited nearly equal total FTF activities (Table 4). However, the transglycosylation: hy- drolysis ratio was about four times higher for the cellassociated enzyme than that of the free enzyme present in the supernatant. By contrast, virtually all the FTF activity of L. gasseri DSM 20077 was cell-wall-associated, displaying equal transglycosylation and hydrolytic activity. Although relatively low, FTF activity (measured as glucose and fructose release) was also detected for L. gasseri 20243 cells. Neither fructan nor FOS production was observed for this strain, not even after long incubation times with sucrose, reflecting the inactive status of the InuGA enzyme. The measured activity might have resulted from the action of two putative glycoside hydrolase family GH32 proteins (http://www.cazy.org/fam/GH32.html) in L. gasseri DSM 20243, LGAS_0399 (GenBank accession no. ABJ59804.1) and LGAS_1779 (GenBank accession no. ABJ61066.1), both annotated as sucrose-6-phosphate hydrolases, causing sucrose hydrolysis. In our FTF enzyme activity assays, we used 0.1 vols $1 \mathrm{M} \mathrm{NaOH}$ to stop the reactions. Although the absence of signal sequences suggests that these enzymes are intracellular, it is most likely that their products become released due to cell lysis by $\mathrm{NaOH}$ treatment and that they contributed to the measured sucrose hydrolytic activity.

\section{Conclusions}

Synthesis of fructose polysaccharides (fructans) and/or oligosaccharides (FOS) from sucrose, involving fructansucrase enzymes, is one of the potential factors that confer a

Table 3. Quantitative analysis of the various products synthesized by the purified $L$. gasseri FTF enzymes (each supplied at $100 \mathrm{U} I^{-1}$ ) from sucrose $(600 \mathrm{mM})$ during incubation for 7 days at $37{ }^{\circ} \mathrm{C}$

Values shown are means $\pm \mathrm{SD}$ of the results obtained from three independent experiments.

\begin{tabular}{|c|c|c|c|c|c|}
\hline FTF enzyme & $\begin{array}{l}\text { Sucrose consumed } \\
\qquad(\%)^{\star}\end{array}$ & $\begin{array}{l}\text { Free glucose } \\
\qquad\left(\mathrm{g} \mathrm{l}^{-1}\right)\end{array}$ & $\begin{array}{l}\text { Free fructose } \\
\qquad\left(\mathrm{g} \mathrm{l}^{-1}\right)\end{array}$ & $\begin{array}{l}\text { Fructose incorporated in fructan } \\
\text { polymer }\left(\mathrm{g} \mathrm{l}^{-1}\right)\end{array}$ & $\begin{array}{l}\text { Fructose incorporated in } \\
\text { FOS }\left(\mathrm{g} \mathrm{l}^{-1}\right)\end{array}$ \\
\hline InuGA-RM & $78 \pm 0.6$ & $73 \pm 1.7$ & $14 \pm 0.8$ & $18 \pm 2.1$ & $41 \pm 2.9$ \\
\hline InuGB-R & $91 \pm 1.2$ & $85 \pm 1.3$ & $16 \pm 0.7$ & $20 \pm 1.8$ & $49 \pm 3.3$ \\
\hline LevG-R & $66 \pm 1.7$ & $63 \pm 1.0$ & $30 \pm 0.8$ & $22 \pm 0.9$ & $11 \pm 1.6$ \\
\hline
\end{tabular}

${ }^{\star}$ Percentage of the total $(600 \mathrm{mM})$ sucrose used. 
Table 4. FTF enzyme activities $\left(\mathrm{U} \mathrm{ml}^{-1}\right)$ of $L$. gasseri strains (with sucrose as substrate) on the surfaces of washed $L$. gasseri cells (the DSM 20604 FTF enzyme has no cell anchoring LPXTG motif), as well as in their dialysed culture supernatants

Values are the means \pm SD of the results from three independent experiments.

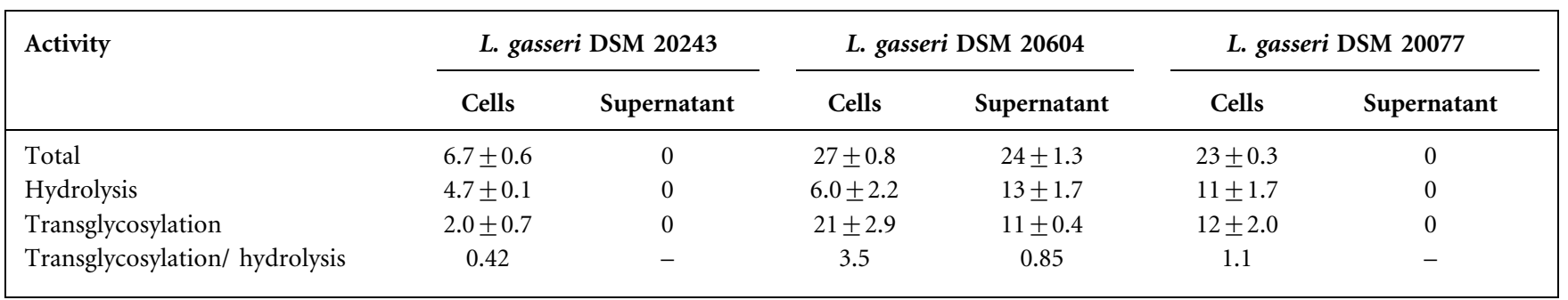

probiotic role(s) to several lactobacilli. In this work, we have studied three different L. gasseri strains from the DSMZ culture collection, including the type strain, and found considerable heterogeneity among their ftf/FTF genes/ enzymes and the fructan products synthesized. These data provide important novel insights into the variation in properties occurring between closely related strains. The $L$. gasseri type strain (DSM 20243) did not synthesize any fructan product, apparently because it harbours an $\mathrm{ft} f$ gene with a preliminary stop codon rendering it inactive. Replacement of the stop codon with a glutamine codon resulted in an active inulosucrase gene of a normal length; the recombinant InuGA-RM enzyme converted sucrose into inulin poly- and oligosaccharides. The L. gasseri strain DSM 20604 clearly synthesized both inulin poly- and oligosaccharides, products of its inulosucrase enzyme InuGB. Strain DSM 20604 produced a broad range of FOS of the inulin type ranging from DP2-DP13; the larger FOS particularly are not produced in similar quantities by other bacteria, nor by their purified FTF enzymes. The InuGB protein lacks the cell-anchoring-motif resulting in a partly free and partly cellassociated status. Strain DSM 20077 synthesized a levan polysaccharide, the product of its levansucrase enzyme LevG. Sequence analysis showed that the overall domain organization of the InuGA, InuGB and LevG proteins was similar to those for FTFs of other lactobacilli. An interesting feature of the L. gasseri strains is that they were unable to ferment raffinose, whereas their respective recombinant enzymes used raffinose as a substrate.

\section{ACKNOWLEDGEMENTS}

The work presented here is a part of the $\mathrm{PhD}$ studies of M.A.A., funded by a scholarship from the Higher Education Commission (HEC), Government of Pakistan. We thank Peter Sanders for HPAEC analysis and Pieter van der Meulen (Department of Biophysical Chemistry) for his technical support in NMR spectroscopy. H.L. thanks the NWO (Netherlands Organization for Scientific Research) for financial support.

\section{REFERENCES}

Anwar, M. A., Kralj, S., Van der Maarel, M. J. \& Dijkhuizen, L. (2008). The probiotic Lactobacillus johnsonii NCC 533 produces high- molecular-mass inulin from sucrose by using an inulosucrase enzyme. Appl Environ Microbiol 74, 3426-3433.

Armuzzi, A., Cremonini, F., Bartolozzi, F., Canducci, F., Candelli, M., Ojetti, V., Cammarota, G., Anti, M., De, L. A. \& other authors (2001). The effect of oral administration of Lactobacillus GG on antibioticassociated gastrointestinal side-effects during Helicobacter pylori eradication therapy. Aliment Pharmacol Ther 15, 163-169.

Azcarate-Peril, M. A., Altermann, E., Goh, Y. J., Tallon, R., SanozkyDawes, R. B., Pfeiler, E. A., O'Flaherty, S., Buck, B. L., Dobson, A. \& other authors (2008). Analysis of the genome sequence of Lactobacillus gasseri ATCC 33323 reveals the molecular basis of an autochthonous intestinal organism. Appl Environ Microbiol 74, 46104625.

Ben Ammar, Y., Matsubara, T., Ito, K., lizuka, M., Limpaseni, T., Pongsawasdi, P. \& Minamiura, N. (2002). Characterization of a thermostable levansucrase from Bacillus sp. TH4-2 capable of producing high molecular weight levan at high temperature. J Biotechnol 99, 111-119.

Chipperfield, A. R. \& Taylor, D. M. (1970). Binding of plutonium to glycoproteins in vitro. Radiat Res 43, 393-402.

Conway, P. L., Gorbach, S. L. \& Goldin, B. R. (1987). Survival of lactic acid bacteria in the human stomach and adhesion to intestinal cells. J Dairy Sci 70, 1-12.

Fischetti, V. A., Pancholi, V. \& Schneewind, O. (1990). Conservation of a hexapeptide sequence in the anchor region of surface proteins from Gram-positive cocci. Mol Microbiol 4, 1603-1605.

Homann, A., Biedendieck, R., Gotze, S., Jahn, D. \& Seibel, J. (2007). Insights into polymer versus oligosaccharide synthesis: mutagenesis and mechanistic studies of a novel levansucrase from Bacillus megaterium. Biochem J 407, 189-198.

Itoh, T., Fujimoto, Y., Kawai, Y., Toba, T. \& Saito, T. (1995). Inhibition of food-borne pathogenic bacteria by bacteriocins from Lactobacillus gasseri. Lett Appl Microbiol 21, 137-141.

Kirjavainen, P. V., Ouwehand, A. C., Isolauri, E. \& Salminen, S. J. (1998). The ability of probiotic bacteria to bind to human intestinal mucus. FEMS Microbiol Lett 167, 185-189.

Kirjavainen, P. V., El-Nezami, H. S., Salminen, S. J., Ahokas, J. T. \& Wright, P. F. (1999). The effect of orally administered viable probiotic and dairy lactobacilli on mouse lymphocyte proliferation. FEMS Immunol Med Microbiol 26, 131-135.

Korakli, M., Ganzle, M. G. \& Vogel, R. F. (2002). Metabolism by bifidobacteria and lactic acid bacteria of polysaccharides from wheat and rye, and exopolysaccharides produced by Lactobacillus sanfranciscensis. J Appl Microbiol 92, 958-965.

Kullen, M. J., Sanozky-Dawes, R. B., Crowell, D. C. \& Klaenhammer, T. R. (2000). Use of the DNA sequence of variable regions of the $16 \mathrm{~S}$ 
rRNA gene for rapid and accurate identification of bacteria in the Lactobacillus acidophilus complex. J Appl Microbiol 89, 511-516.

Martinez-Fleites, C., Ortiz-Lombardia, M., Pons, T., Tarbouriech, N., Taylor, E. J., Arrieta, J. G., Hernandez, L. \& Davies, G. J. (2005). Crystal structure of levansucrase from the Gram-negative bacterium Gluconacetobacter diazotrophicus. Biochem J 390, 19-27.

Meng, G. \& Futterer, K. (2003). Structural framework of fructosyl transfer in Bacillus subtilis levansucrase. Nat Struct Biol 10, 935-941.

Meng, G. \& Futterer, K. (2008). Donor substrate recognition in the raffinose-bound E342A mutant of fructosyltransferase Bacillus subtilis levansucrase. BMC Struct Biol 8, 16.

Morales-Arrieta, S., Rodriguez, M. E., Segovia, L., Lopez-Munguia, A. \& Olvera-Carranza, C. (2006). Identification and functional characterization of levS, a gene encoding for a levansucrase from Leuconostoc mesenteroides NRRL B-512 F. Gene 376, 59-67.

Oda, M., Hasegawa, S., Komatsu, S., Kambe, M. \& Tsuchiya, M. (1983). Anti-tumor polysaccharide from Lactobacillus sp. Agric Biol Chem 47, 1623-1625.

Olivares-Illana, V., Wacher-Rodarte, C., Le Borgne, S. \& LópezMunguía, A. (2002). Characterization of a cell-associated inulosucrase from a novel source: a Leuconostoc citreum strain isolated from Pozol, a fermented corn beverage of Mayan origin. J Ind Microbiol Biotechnol 28, 112-117.

Olvera, C., Centeno-Leija, S. \& Lopez-Munguia, A. (2007). Structural and functional features of fructansucrases present in Leuconostoc mesenteroides ATCC 8293. Antonie Van Leeuwenhoek 92, 11-20.

Ozimek, L. K., van Hijum, S. A., van Koningsveld, G. A., Van der Maarel, M. J., Van Geel-Schutten, G. H. \& Dijkhuizen, L. (2004). Sitedirected mutagenesis study of the three catalytic residues of the fructosyltransferases of Lactobacillus reuteri 121. FEBS Lett 560, 131-133.

Ozimek, L. K., Euverink, G. J., Van der Maarel, M. J. \& Dijkhuizen, L. (2005). Mutational analysis of the role of calcium ions in the Lactobacillus reuteri strain 121 fructosyltransferase (levansucrase and inulosucrase) enzymes. FEBS Lett 579, 1124-1128.

Ozimek, L. K., Kralj, S., Kaper, T., Van der Maarel, M. J. \& Dijkhuizen, L. (2006a). Single amino acid residue changes in subsite -1 of inulosucrase from Lactobacillus reuteri 121 strongly influence the size of products synthesized. FEBS J 273, 4104-4113.

Ozimek, L. K., Kralj, S., Van der Maarel, M. J. \& Dijkhuizen, L. (2006b). The levansucrase and inulosucrase enzymes of Lactobacillus reuteri 121 catalyse processive and non-processive transglycosylation reactions. Microbiology 152, 1187-1196.

Pedrosa, M. C., Golner, B. B., Goldin, B. R., Barakat, S., Dallal, G. E. \& Russell, R. M. (1995). Survival of yogurt-containing organisms and Lactobacillus gasseri (ADH) and their effect on bacterial enzyme activity in the gastrointestinal tract of healthy and hypochlorhydric elderly subjects. Am J Clin Nutr 61, 353-359.

Pridmore, R. D., Berger, B., Desiere, F., Vilanova, D., Barretto, C., Pittet, A. C., Zwahlen, M. C., Rouvet, M., Altermann, E. \& other authors (2004). The genome sequence of the probiotic intestinal bacterium Lactobacillus johnsonii NCC 533. Proc Natl Acad Sci U S A 101, 2512-2517.

Rosell, K. G. \& Birkhed, D. (1974). An inulin-like fructan produced by Streptococcus mutans strain JC2. Acta Chem Scand B 28, 589.

Sambrook, J., Fritsch, E. F. \& Maniatis, T. (1989). Molecular Cloning: a Laboratory Manual. New York: Cold Spring Harbour Laboratory.
Schwab, C., Walter, J., Tannock, G. W., Vogel, R. F. \& Ganzle, M. G. (2007). Sucrose utilization and impact of sucrose on glycosyltransferase expression in Lactobacillus reuteri. Syst Appl Microbiol 30, 433443.

Shimamura, A., Tsuboi, K., Nagase, T., Ito, M., Tsumori, H. \& Mukasa, H. (1987). Structural determination of D-fructans from Streptococcus mutans, serotype $b, c, e$, and $f$ strains, by ${ }^{13} \mathrm{C}-$ n.m.r. spectroscopy. Carbohydr Res 165, 150-154.

Tejada-Simon, M. V. \& Pestka, J. J. (1999). Proinflammatory cytokine and nitric oxide induction in murine macrophages by cell wall and cytoplasmic extracts of lactic acid bacteria. J Food Prot 62, 1435-1444.

Thompson, J. D., Higgins, D. G. \& Gibson, T. J. (1994). CLUSTAL W: improving the sensitivity of progressive multiple sequence alignment through sequence weighting, position-specific gap penalties and weight matrix choice. Nucleic Acids Res 22, 4673-4680.

Tieking, M., Ehrmann, M. A., Vogel, R. F. \& Ganzle, M. G. (2005). Molecular and functional characterization of a levansucrase from the sourdough isolate Lactobacillus sanfranciscensis TMW 1.392. Appl Microbiol Biotechnol 66, 655-663.

Trujillo, L. E., Gomez, R., Banguela, A., Soto, M., Arrieta, J. G. \& Hernández, L. (2004). Catalytical properties of $N$-glycosylated Gluconacetobacter diazotrophicus levansucrase produced in yeast. Electron J Biotechnol 7, 116-123.

Van Geel-Schutten, G. H., Faber, E. J., Smit, E., Bonting, K., Smith, M. R., Ten Brink, B., Kamerling, J. P., Vliegenthart, J. F. \& Dijkhuizen, L. (1999). Biochemical and structural characterization of the glucan and fructan exopolysaccharides synthesized by the Lactobacillus reuteri wild-type strain and by mutant strains. Appl Environ Microbiol 65, 3008-3014.

van Hijum, S. A. F. T., Bonting, K., Van der Maarel, M. J. E. C. \& Dijkhuizen, L. (2001). Purification of a novel fructosyltransferase from Lactobacillus reuteri strain 121 and characterization of the levan produced. FEMS Microbiol Lett 205, 323-328.

van Hijum, S. A. F. T., Van Geel-Schutten, G. H., Rahaoui, H., Van der Maarel, M. J. \& Dijkhuizen, L. (2002). Characterization of a novel fructosyltransferase from Lactobacillus reuteri that synthesizes highmolecular-weight inulin and inulin oligosaccharides. Appl Environ Microbiol 68, 4390-4398.

van Hijum, S. A. F. T., Van der Maarel, M. J. \& Dijkhuizen, L. (2003). Kinetic properties of an inulosucrase from Lactobacillus reuteri 121. FEBS Lett 534, 207-210.

van Hijum, S. A. F. T., Szalowska, E., Van der Maarel, M. J. \& Dijkhuizen, L. (2004). Biochemical and molecular characterization of a levansucrase from Lactobacillus reuteri. Microbiology 150, 621-630.

van Hijum, S. A. F. T., Kralj, S., Ozimek, L. K., Dijkhuizen, L. \& van Geel-Schutten, I. G. (2006). Structure-function relationships of glucansucrase and fructansucrase enzymes from lactic acid bacteria. Microbiol Mol Biol Rev 70, 157-176.

Wada, T., Ohguchi, M. \& Iwai, Y. (2003). A novel enzyme of Bacillus sp. $217 \mathrm{C}-11$ that produces inulin from sucrose. Biosci Biotechnol Biochem 67, 1327-1334.

Waldherr, F. W., Meissner, D. \& Vogel, R. F. (2008). Genetic and functional characterization of Lactobacillus panis levansucrase. Arch Microbiol 190, 497-505.

Edited by: V. Eijsink 